\title{
Effects of Three Selected Pesticides on the Non-Biting Midges (Diptera: Chironomidae) in Rice Agro-Ecosystem of an area of West Bengal; India
}

\author{
Bappaditya Pan \\ Department of Bio-Medical Laboratory Science and Management \\ Vidyasagar University, Midnapore, West Bengal 721102, India \\ Tel: 91-3222-276554 (Extn. 484)Ｅ-mail: bappapan@ gmail.com
}

Uttaran Majumdar

Department of Zoology

Hooghly Women's College, Hooghly, West Bengal 712103, India

Tel: 91-33-26805033 E-mail: uttaran11@gmail.com

Lipirani Jana

Department of Bio-Medical Laboratory Science and Management

Vidyasagar University, Midnapore, West Bengal 721102, India

Tel: 91-3222-276554 (Extn. 484)Ｅ-mail: jana.lipi@gmail.com

Sandip Chattopadhyay (Corresponding author)

Department of Bio-Medical Laboratory Science and Management

Vidyasagar University, Midnapore, West Bengal 721102, India

Tel: 91-3222-276554 (Extn. 484) E-mail: sandipdoc@yahoo.com

Received: July 7, 2016 Accepted: July 17, 2016 Published: June 4, 2017

doi:10.5296/jee.v8i1.9678 URL: https://doi.org/10.5296/jee.v8i1.9678 


\begin{abstract}
Deformities of non biting midge larvae's mouthparts are considered as indicators of environmental degradation that caused by water pollutants like pesticides, heavy metals, organic contaminants etc. The present investigation was aimed to assess the effects of 3 pesticides, viz. Cartap Hydrochloride, Carbofuran and Fipronil on deformities of chironomid larvae of the Rice fields of Village Dhunui; Memari Block-II of Burdwan district in West Bengal. The study area is dominated by the species of the genus Chironomus of chironomid community. Concurrently six (6) species were considered. The average percentage of mouthpart deformities was $14 \%$ in all chironomid larvae. Highest degree of malformation was noticed in Chironomus circumdatus in which more than $18.90 \%$ of all specimens were affected. However, further investigative efforts are essential to investigate the actual explanation in support of the occurrence of high degree of deformities in chironomid.
\end{abstract}

Keywords: Chironomidae, Deformity, Pesticides, Pollution, Rice field 


\section{Introduction}

A good amount of works on Indian chironomids has been carried out on the systematics, biology, ecology and to some extent on deformities. Useful keys have also been designed for quick and correct identification of various stages of development (Bhattacharya et al. 1999, 2005, 2006; Chaudhuri and Chattopadhyay 1988, 1990; Chaudhuri and Ghosh 1986; Chaudhuri et al. 1992, 2001; Danks 1971; Guha et al. 1982). The rice cultivation in the country now a day has been facing acute problem due to rapid population explosion and industrialization resulting changes in the ecosystems. Though a large amount of pesticides and fertilizer is in use for better production of crop, the rice fields of West Bengal were not in the lime light area and almost all the rice fields are polluted for aquatic invertebrates due to indiscriminate use of pesticides. Other than river and ponds the largest land areas occupied by rice agro-ecosystem in West Bengal and that is the main site for growth of chironomid population, because most of the time that system are wet in nature. Al-Saffar (2008) found that the distorted pecten epipharyngis was the probable outcome of the contamination of either DDT or heavy metals $(\mathrm{Cu}$ and $\mathrm{Pb})$.

Warwick (1985), opined that the decisive index of severity of Chironomus larvael malformation are based on antennal deformities (ISAD) while the toxic score index (TSI) anticipated by Lenat (1993) is due to the mentum malformation.

Al-Shami et al. (2010) demonstrated that the high level of mentum deformity in Chironomus. ranging from $20-30 \%$ whereas deformity percentage of mandible is nearly $3-4 \%$. The incidence of deformities for the population of clean environments in periods under the anthropogenic and enormous industrial activities has been approximated at a range of $0 \%$ to 0.8\% (Warwick 1980; Wiederholm 1984) whereas deformation of the midges surviving in unpolluted environments or in water bodies with minimum toxicant load was estimated to be around 8\% (Bird 1994; Madden et al. 1992; Veroli et al. 2012; Warwick 1985; Wiederholm 1984). However, deformity has been found with a high value in maximal contaminated sites comprising at a range of $33 \%$ to $57 \%$ (Veroli et al. 2010).

Deformities can be expressed as disappearance of original morphological features (Warwick 1988). Effects created by mechanical wear, rupture or abrasion are the frequently occurring phenomena of the mouthparts under a stressful condition mediated by solid substrate surfaces, mineral particles and sclerotized organic materials (Janssens de Bisthoven et al. 1992; Vermeulen 1995).

Morphological deformities in larval head capsules of the polluted environments advocate an association between pollution and deformities (Janssens de Bisthoven et al. 1998; Servia et al. 2000; Vermeulen 1995). In this manuscript we would intend to investigate the changes of the mouth part of the Chironomidaes larva after organic pesticides exposure.

\section{Materials and Methods}

\subsection{Study Area}

The study area was located in the village Dhunui; Memari Block-II of Burdwan district, West 
Bengal, India. The district Burdwan is sited on the west bank of Hooghly River, away from $60 \mathrm{~km}$ north of Kolkata. This district is an entirely flat land with an approximate maximum elevation of 200 meters. The study area $\left(23^{\circ} 21^{\prime} \mathrm{N}\right.$ and $\left.88^{\circ} 12^{\prime} \mathrm{E}\right)$ is located in Memari II Block of Burdwan Sadar South sub-division of Burdwan district. Memari is predominantly an agricultural area and except rice mills there was no industry in this area. The cultivation of rice in this area occurred during two seasons of the year; January to March comprising the Boro season while July to September is the Aman season. Field sampling Monthly samples of immature Chironomidae were randomly collected from 2012 to 2014. Adult chironomids around the sampling sites were collected by using a sweep net. Using scrapers and scoop sampler larvae were obtained from muddy soil of the rice fields (Chaudhuri and Chattopadhyay, 1990). Each sample was transferred to a polymer bucket and followed by washing with water and passed through a sieve (300 $\mu \mathrm{m}$ pore). The residue on the sieve including immature chironomids was shifted to a white enamel tray.

On several occasions, chironomid egg masses adhering to twigs at the sampling sites were collected from water surface by using a small brush. On each sampling occasion, field-collected immature chironomids were carried to the laboratory for sorting in containers filled with aerated water following the method of Pinder (1983).

\subsection{Collection of Physico-Chemical Data}

The physico-chemical parameters were measured at each sampling site during 2012 and 2014 as described in Bhattacharya et al. (2006) and Chaudhuri and Chattopadhyay (1990). Parameters, such as $\mathrm{pH}$, temperatures, dissolved oxygen (DO) and biochemical oxygen demand (BOD) were documented at the sampling area with the portable $\mathrm{pH}$ meter (pH-ep, HI- 98107, HANNA), hand-held thermometer and digital DO meter (LT-Lutron-DO-5509) respectively. BOD was calculated following standard protocol described by APHA, 1998.

\subsection{Sorting and Preservation of Live Specimens}

Adult midges collected from insect net were directly transferred into $70 \%$ alcohol in vials labeled individually for the preservation and transportation to the laboratory for microscopical examination. Intact egg masses of midges were transported in living condition in the properly labelled plastic containers. Small amount of water of particular site was added to the container and provide aeration through automatic air pump. Larvae and pupae were sorted out from soil sample following the techniques of Dickman et al (1992) and the sorted larvae were categorized into two groups, 1st group of $70-75 \%$ collected larvae were directly potted in $70 \%$ alcohol and shifted to the laboratory for microscopical observation whereas the rest $25-30 \%$ larvae were transported alive to the laboratory with sediment and water of collecting sites for laboratory experiment.

\subsection{Laboratory Rearing}

For laboratory rearing of field-collected larvae, 30-40 petri dishes (8-12 $\mathrm{cm}$ in diameter) enclosed with long tube-like transparent plastic with a mesh lid at the top (20-25 cm tall and $8-12 \mathrm{~cm}$ in diameter) were used. These petri dishes were utilized as containers for rearing of 
4-5 third or fourth instar chironomid larvae to obtain various life stages. Prior to laboratory rearing, the larvae were allowed to acclimatize for 24 hours in the laboratory.

\subsection{Preservation}

Chironomid immature stages and adults were collected from the field as well as from the laboratory experimental units were preserved and stored in 70-90\% ethyl alcohol. Kahle's solution was used to preserve natural colour for both immature and adult specimens.

\subsection{Mounting and Slides Preparation}

The phenol-balsam technique as expressed by Wirth and Marston (1968) was chiefly employed for preparation of microslides of larvae, pupae, and adults. Similarly, larval and pupal exuviae were also mounted on microslides in phenol-balsam.

The head capsules were positioned ventrodorsally on the slide, whereas the body was adjusted horizontally with its dorsal side up. The microslide-mounts of all specimens were placed on a hot plate $\left(35-45^{\circ} \mathrm{C}\right)$ for drying.

\subsection{Measurements and Photographs}

Different larval and adult parts were measured under a compound microscope equipped with a micrometer. All measurements were taken in millimeters $(\mathrm{mm})$ with the mean value written before parentheses while those within parentheses indicate minimum and maximum followed by ' $n$ ' being the number of specimen considered. Various larvael parts' deformities were photographed and analyzed by employing Trinocular Microscope Leica-DM200. For Scanning Electron Microscope (SEM) study of chironomid, specimens were prepared following Bozzola and De Russel (1999) as described in Kownacki et al. (2015). Images were captured in Hitachi-S530 at University Science Instrumentation Centre (USIC) at the University of Burdwan.

\section{Results}

\subsection{Physico-Chemical Parameters}

Physico-chemical variables taken during 2012-2014 are presented in (Table 1). Relative humidity ranges from $95 \%$ (September, 2012) to 30\% (February, 2014) while highest air temperature observed $34^{\circ} \mathrm{C}$ (July, 2013) and the lowest $10^{\circ} \mathrm{C}$ (January, 2013). Similarly the water temperature varied from $28^{\circ} \mathrm{C}$ (July, 2013) to $15^{\circ} \mathrm{C}$ (January, 2014). The water $\mathrm{pH}$ ranged from 6.9 to 7.6, while the soil $\mathrm{pH}$ varied from 5.2 to 6.4. The Dissolved Oxygen (DO) was highest in April, 2012 (8.3 mg/l) compared to the lowest in July, 2012 (4.3 mg/l).

\subsection{Percentage of Occurrence of Larval Deformities}

Morphological deformities were studied in 6 taxa of chironomid larvae of rice agroecosystems. Out of the total deformity the highest percentage of deformities (14.37\%) was found in Boro season of 2014, whereas 9.9\% in Aman season of 2012 appears to be the least (Fig.1). Larvae collected from the field treated with different pesticides showed that the level of deformity was almost similar (16.5\%, 17.2\% and 17.3\%) (Fig. 2). Five taxa of chironomid 
larvae (C. circumdatus, C. javanus, C. samoensis, $K$. barbatitarsis and $K$. calligaster were examined $(n=1766)$ for deformity in Aman season of 2012 and observed only $9.9 \%$ are deformed larvae (Fig. 1). The occurrence of deformity in C. circumdatus was $14.43 \%, C$. javanus was $6.67 \%$, C. samoensis was $8.89 \%, K$. barbatitarsis was $8.50 \%$ and $K$. calligaster was $9.09 \%$. In Boro season of 2013, only 4 taxa (C. circumdatus, $C$. striatipennis, $K$. barbatitarsis and $K$. calligaster $)$ of chironomid larvae $(\mathrm{n}=1585)$ were examined for deformity and observed only $12.7 \%$ deformed larvae (Fig 1). The occurrence of deformities was observed in C. circumdatus (21.33\%), C. striatipennis (8.29\%), K. barbatitarsis $(6.23 \%)$ and $K$. calligaster $(9.63 \%)$. Deformation in the larval body parts were examined $(\mathrm{n}=1211)$ in 5 taxa (C. circumdatus, C. javanus, $C$. samoensis, $K$. barbatitarsis and $K$. calligaster) in Aman season of 2013 and observed 13\% deformed larvae (Fig. 1). The occurrence of deformity in C. circumdatus was $21.86 \%, C$. javanus was $8 \%, C$. samoensis was $9.89 \%, K$. barbatitarsis was $8.39 \%$ and $K$. calligaster was $7.58 \%$. Four taxa of chironomid larvae $(C$. circumdatus, C. javanus, $C$. striatipennis and $K$. Barbatitarsis) were examined (n=1677) for deformity in Boro season of 2014 and observed $14.37 \%$ are deformed larvae (Fig. 1). Out them C. circumdatus was $18.15 \%, C$. javanus was $15.73 \%$, C. striatipennis was $11.11 \%$ and K. Barbatitarsis was $12.14 \%$. Seasonal variation of deformities in response to different pesticides revealed that all the 3 pesticides had shown least effect in Aman season of 2012. Deformities in the field treated with Cartap Hydrochloride and Carbofuran were highest in Boro season of 2014 while that of Fipronil was more or less similar in Boro season of 2013, Aman season of 2013 and Boro season of 2014.

\subsection{Morphological Deformities in the Larvae}

Morphological deformities of the chironomid larvae were found to vary from species to species depending on the different sensory structures. Generally head capsules and mouthparts were highly affected rather than other parts showing high rate of deformities in mentum, antenna, mandibles and pecten epipharyngis. But the types of severity of deformities of all the structures were not always same even in the same species as evident in the photographs obtained in scanning electron microscope (Fig.3). During the investigation of four seasons, significant differences were observed in severity in three different sites of rice agro-ecosystem. Identification of larvae up to species level was not possible, types of deformity had been categorized up to generic level following indexing scheme of Warwick (1985). The occurrence of deformity in 6 taxa in 4 seasons showed that the highest percentage of deformity found in Chironomus circumdatus. Thus the types and severity of deformities had been calibrated in Chironomus circumdatus.

\section{Discussion}

The basic interest of pollution is envisaged on its effect on living beings; hence assessment of pollution by using biological organisms appears troublesome. Traditional assessment of pollution had been chemically oriented but the biological aspects of the problem remained ill attended simply due to descriptive features and lack of numerical data. Ecosystem under stress displays a set of warning signs of suffering and those were correlated with variations of primary yield, species diversity and incidence of 
deformities. Although the earliest warning of environmental denotation provided potentiality in the organism level, it seemed doubtful to achieve all the biological phenomena with single measurement (Johnson et al. 1993). Physico- chemical factors, contamination of water and soil play a key role in influencing the allocation of species. According to Ali et al. (2002), a direct correlation exists between different physical and chemical factors influencing the sediment and the water of lake. The field shows broad ranges in physico-chemical parameters such as, temperature, $\mathrm{pH}$, dissolved oxygen and BOD due to its shallow nature and inputs of nutrients (Lim 1990). The parameters have been found to vary though out the work.

Che Salmah et al. (1998) explored that the water temperature of a rain fed rice field is within a range of $26.4-39.7^{\circ} \mathrm{C}$. The amount of dissolved oxygen of the rice paddies increases in response to photosynthesis and presence of algal populations. In the present investigation, the dissolved oxygen is moderately low in July (4.3-5.7 mg/l) compared to August (7.5-8.3 mg/l). Che Salmah et al. (1998) have documented that dissolved oxygen levels in rain fed rice field vary considerably between 1.65-5.68 mg/l. However, Lim et al. (1984) have found very high dissolved oxygen in Malaysian rice field with a mean value of $8.6 \mathrm{mg} / \mathrm{l}$. Likewise, Fores (1992) has noticed a broad range of dissolved oxygen from 2.83 to $11.1 \mathrm{mg} / \mathrm{l}$ in the Netherlands rice field.

Usually, the $\mathrm{pH}$ range in paddy fields fluctuates following rice phases at the time of cultivation (Fores 1992). In the present investigation, the mean $\mathrm{pH}$ was noted to show slightly acidic. But slightly acidic $\mathrm{pH}$ has been noticed in rice fields of Malaysia (Lim et al. 1984, Che Salmah et al. 1998). The acidity of the soil of the rice field is the dual effect of application of herbicides and rice stalks of previous season that remains in the decomposed form (Ali and Ahmad 1988).

Alternating changes in chemical and physical characteristics of the rice field water may be the consequence of rice fields like other aquatic ecosystem, the nutrient rotation and ecological interaction between the aquatic communities. Moreover, the agriculture practices in the rice field such as ploughing, harvesting and application of chemicals; appear to have an important role in physical and chemical alteration of the quality of the field water.

Deformities in four structures viz, mentum and antenna, were studied in generic and species levels in some cases.

A direct association exists between deformities of head capsules of the worms suffered due to pesticide polluted sediment (Arambourou et al. 2013; Bhattacharyay et al. 2005, 2006; Janssens de Bisthoven et al. 1992; Warwick 1985, 1990; Warwick and Tisdale 1988; Wiederholm 1984).

According to Warwick (1990), deformities occured in the species Cryptotendipes sp. and $K$. calligaster. Whereas Al-Shami et al. (2010) has shown high prevalence of deformity in Chironomus sp. Larvae in Malaysia.

Deformities were evident in Chironomus riparius (Servia et al. 2004a, b), C. plumosus (Amiryan 2010, Veroli et al. 2012), C. riparius (Arambourou et al. 2012) and C. sancticaroli 
(Rebechi and Navarro- Silva 2012). In this study various types of deformities were analyses in $C$. circumdatus, and $K$. calligaster larvae. Head capsules of $C$. circumdatus has been found to be affected undergo severely and are proved as tolerant and well adjusted dominant species among all other chironomid taxa. Janssens de Bisthoven and Gerhardt (2003) recommended that exploration of morphological deformities in individual organisms may prove helpful in deciding the biological effects of contaminants in aquatic ecosystems even though there is a paucity of information regarding the responsiveness of individual organisms against contaminants. It is postulated that different deformities may be allied with specific chemicals (Warwick and Tisdale 1988) or amalgamation of different chemicals (Veroli et al. 2010). Dickman et al. (1992) has found direct correlation between percentage of deformity and concentration of $\mathrm{Pb}$ of sediment. Janssens de Bisthoven et al. (1992) indicated correlation between deformity of chironomid larvae and heavy metals. Because of the increased levels of metal, coal tar, urban or agricultural runoff, and pesticides; degrees of deformities are also increased (Madden et al. 1992). It is well known that heavy metal pollution is a major detrimental factor behind larval deformities in the chironomid midges (Al-Shami et al. 2010, 2011a; Bhattacharyay et al. 2005; Martinez et al. 2004).

In agreement with Vermeulen (1995), this investigation has observed that Chironomus sp. Midge larval mentum is highly vulnerable to deformation; hence, these deformations are potentially essential indicators of growing water and sediment-bound contaminants (Janssens de Bisthoven and Gerhardt 2003). Biomonitoring of aquatic ecosystems with the application of living organisms has numerous advantages over traditional water quality chemical analyses. Freshwater organisms survive incessantly in the aquatic environment and respond to all environmental detrimental factors in combination with pollutants synergistically (Morse et al. 2007).

Hamilton and Sæther (1971) recommended that morphological deformities in individual aquatic organisms may be employed as a useful tool to judge the biological effects of contaminants in aquatic ecosystems, although a lacuna of knowledge is there regarding the interaction of contaminants and individual aquatic organisms.

The deformities of head capsule of Chironomus sp. larvae as observed in this study after comparison with those of Warwick and Tisdale (1988), and Bird (1994) showed widespread anomaly in the mentum and antenna of Chironomus sp. larvae in all experimental sites.

The occurrence of larval deformities in chironomids seems to be the upshot of general stress response against an extensive range of environmental contaminants (Bird 1997; Vermeulen 1995). Therefore, incidences of deformities at a particular site point out the overload of contaminants at that site. As stated in different literature the numerous substances alone or in combination may raise morphological deformation specifically in pesticides, but no specific substance has yet to be identified as limiting factor (Wiederholm 1984). According to Bird (1994) deformities of this extent are much higher (30\%) in a polluted river in Canada. Dermott (1991) documented that there is no discrete evidence that could resolve which of the different industrial and agricultural chemicals encourage deformation in the chironomid larvae. However, Warwick (1985) and Warwick and Tisdale (1988) have put 
forward the relationship between contaminated sediments and deformities in Chironomus spp. larvae. Suffering of deformities in the larvae of Chironomus spp. and the severity of their response are linked to extensive uses of radioactive materials, heavy metals, and pesticides (Warwick 1985, Warwick and Tisdale 1988).

Al-Shami et al. (2011a) recorded deformity percentage amounting $33.71 \%$ in the larvae of Chironomus spp.

Dickman et al. (1992) reported amplification in the occurrence of deformities is linked with high levels of metal, coal tar, urban or agricultural run-off, and pesticides. Madden et al. (1992) pointed out a significant association between the deformities of antennal and mouth parts in larval chironomids and the concentrations of DDT and the herbicide, Dacthal. Mouthpart is frequently applied to screen the quality of sediments in freshwater environments. Deformities in the mentum, antenna and mandible show the signs of high, medium, and low levels of contamination. The total deformities are closely correlated with deformities of mentum but are not too significant in other parts of head capsule (Al-Shami et al. 2010). Severity indices are also variable.

Various types of deformities exist among chironomids, and specific contaminants could be the contributing agent for some forms of deformities (Hamilton and Sæther 1971). Vermeulen (1995) has shown that the gap between teeth of mentum seem to be different in response to different pollutants. It is also reported that heavy metals are more toxic agent for this deformity than that of domestic sewage or agricultural runoff (Koehn and Frank 1980). The occurrences of mouthparts deformities are used in biomonitoring processes in polluted aquatic ecosystem (Amiryan 2010; Al-Shami et al. 2011a, 2011b; Morais et al. 2010). Deformities in antennae, mentum, mandibles and pectin epipharyngis were documented in Procladius, Chironomus and Cryptochironomus (Warwick 1991), and were considered as indicators of pesticide and organic pollution (Nazarova et al. 2004). Abnormalities occured at different extents especially in the mentum as a result of exposure of the larvae to heavy metals, agricultural pesticides and fertilizers, and industrial effluents (McDonald and Taylor 2006).

These deformities are similar to those observed in other chironomid cultures (Bird et al. 1995) and in several field studies (Dickman and Rygiel 1996; Janssens de Bisthoven et al. 2001; Warwick and Tisdale 1988; Warwick 1990). No difference has been found in the number of deformities in the pesticides treatments in the laboratory. The occurrence of head capsule deformities in Chironomus larvae expressed in this study appears inadequate and therefore further experiments may pinpoint exact role of pesticide causing deformity in chironomid larvae.

\section{Acknowledgement}

Authors are indebted to Prof. P. K. Chauduri and Prof. A. Mazumdar for their valuable suggestion throughout the work. We are thankful to Dr. Deb Narayan Saha, R.R.R. Mahavidyalaya, Hooghly. We are thankful to USIC at the University of Burdwan to provided SEM facility. 
We are also thankful to Principal of Hooghly Women's College for providing laboratory facilities.

\section{References}

Ali, A. B., \& Ahmad, M. (1988). Water quality in rice field \& sump ponds \& its relationship to phytoplankton growth in rice field fish culture system. Trop. Ecol. 29, 63-70. doi: 10.1023/A:1003511227253

Ali, A., Frouz, J., \& Lobinske, R. J. (2002). Spatio-temporal effects of selected physic-chemical variables of water, algae \& sediment chemistry on the larval community of nuisance Chironomidae (Diptera) in a natural \& manmade lake in central Florida. Hydrobiologia, 470, 181-193. doi:10.1023/A:1015696615939

Al-Saffar, M. A. T. (2008). Larval Mouthpart Deformities in Chironomus annularius Meigen (Diptera, Chironomidae) from Al-Hammar Marsh, Southern Iraq \& Tanjero River, Kurdistan, Northern Iraq. Nature Iraq., 1-12.

Al-Shami, S. A., Che Salmah, M. R., Abu Hassan, A., \& Siti Azizah, M. N. (2011a). Evaluation of mentum deformities of Chironomus spp. (Chironomidae, Diptera) larvae using modified toxic score index (MTSI) to assess the environmental stress in Juru River Basin, Penang, Malaysia. Environ. Monit. Assess., 177, 233-244. https://doi.org/10.1007/s10661-010-1630-1

Al-Shami, S. A., Che Salmah, M. R., Abu Hassan, A., \& Siti Azizah, M. N. (2011b). Fluctuating asymmetry of Chironomus sp. (Diptera, Chironomidae) larvae in association with water quality \& metal pollution in Permatang Rawa River in the Juru River Basin, Penang, Malayasia. Water Air Soil Poll., 216, 203-216. https://doi.org/10.1007/s11270-010-0528-4

Al-Shami, S. A., Che Salmah, M. R., Siti Azizah, M. N., Abu Hassan, A., \& Ali, A. (2010). Morphological deformities in Chironomus spp. (Diptera, Chironomidae) larvae as a tool for impact assessment of anthropogenic \& environmental stresses on three rivers in the Juru River System, Penang, Malaysia. Environ. Entomol., 39(1), 210-222. https://doi.org/10.1603/EN09109

Amiryan, A. L. (2010). Morphological deformities in chironomid larvae (Diptera, Chironomidae) from Hrazdan River, Armenia. J. Nat. Sci., 2(15), 15-17.

Arambourou, H., Beisel, J. N., Branchu, P., \& Debat, V. (2012). Patterns of Fluctuating Asymmetry \& Shape Variation in Chironomus riparius (Diptera, Chironomidae) Exposed to Nonylphenol or Lead. Plos One., 7(11), 1-12. https://doi.org/10.1371/journal.pone.0048844

Arambourou, H., Gismondi, E., Branchu, P., \& Beisel, J. N. (2013). Biochemical \& morphological responses in Chironomus riparius (Diptera, Chironomidae) larvae exposed to lead-spiked sediment. Environ. Toxicol. Chem., 32(11), 1- 7. https://doi.org/10.1002/etc.2336

Bhattacharyay, G., Mazumdar, A., \& Chaudhuri, P. K. (1999). Incidence of deformed Chironomus larvae in contaminated sediment of the River Damodar, West Bengal (Diptera, Chironomidae). Pollut. Res., 18, 79-82. 
Bhattacharyay, G., Sadhu, A. K., Mazumdar, A., \& Chaudhuri, P. K. (2005). Antennal deformities of chironomid larvae \& their use in biomonitoring of heavy metal pollution in the River Damodar of West Bengal, India. Environ. Monit. Assess., 108, 67-84. https://doi.org/10.1007/s10661-005-3963-8

Bhattacharyay, G., Sadhu, A. K., Mazumdar, A., Majumdar, U., Chaudhuri, P. K., \& Ali, A. (2006). Assessment of impact of heavy metals on the communities \& morphological deformities of Chironomidae larvae in the River Damodar (India, West Bengal). Suppl. ad Acta Hydrobiol., 8, 21-32.

Bird, G. A. (1994). Use of chironomid deformities to assess environmental degradation in the Yamaska River, Quebec. Environ. Monit. Assess., 30, 163-175. https://doi.org/10.1007/BF00545620

Bird, G. A. (1997). Deformities in cultured Chironomus tentans larvae \& the influence of substrate on growth, survival \& mentum wear. Environ. Monit. Assess., 45, 273-283. https://doi.org/10.1023/A:1005782803930

Bird, G. A. Rosentreter, M. J. \& Schwartz, W. J. (1995). Deformities in the menta of chironomid larvae from the experimental lakes area, Ontario. Can. J. Fish. Aquat. Sci., 52, 2290-2295. https://doi.org/10.1139/f95-819

Bozzola J. J., \& De Russell L. (1999). Electron Microscopy, Principles \& Techniques for Biologists. Jones \& Bartlett Publishers, Inc

Chaudhuri, P. K., \& Chattopadhyay, S. (1988). Studies on the juveniles of Microchironomus from India (Diptera, Chironomidae). Orient. Ins., 22, 175- 183.

Chaudhuri, P. K., \& Chattopadhyay, S. (1990). Chironomids of the rice paddy areas of West Bengal, India). Tijdschr. Entomol., 133(2), 149-195. Record no. 19910506431

Chaudhuri, P. K., \& Ghosh, M. (1986). Two new species of Kiefferulus Goetghebuer (Diptera, Chironomidae). Syst. Entomol., 11, 277-292.

Chaudhuri, P. K., Das, S. K., \& Sublette, J. E. (1992). Indian species of genus Chironomus Meigen (Diptera, Chironomidae). Zool. Jb. Syst., 119, 1-51. Record no. 19920510729

Chaudhuri, P. K., Hazra, N., \& Alfred, J. R. B. (2001). A check-list of Chironomid midges (Diptera, Chironomidae) of the Indian Subcontinent. Orient. Ins., 35, 335-372. https://doi.org/10.1080/00305316.2001.10417312

Che Salmah, M. R., Hassan, S. T. S., Abu Hassan, A., \& Ali, A. B. (1998). Influence of physical \& chemical factors on the larval abundance of Neurothemis tullia (Drudy) (Odonata, Libellulidae) in a rice field. Hydrobiologia, 389, 193-202. https://doi.org/10.1023/A:1003511227253

Danks, H. V. (1971). Life history \& biology of Einfeldia synchrona (Diptera, Chironomidae). Can. Ent. 103, 1597-1606. http://dx.doi.org/10.4039/Ent1031597-11

Dermott, R. M. (1991). Deformities in larval Procladius sp. \& dominant Chironomini from 
the St. Clair River. Hydrobiologia, 219, 171-185.

Dickman, M., \& Rygiel, G. (1996). Chironomid larval deformity frequencies, mortality \& diversity in heavy metal contaminated sediments of a Canadian riverine wetland. Environ. Int., 22, 693-703. https://doi.org/10.1016/S0160-4120(96)00060-8

Dickman, M., Brindle, I., \& Benson, M. (1992). Evidence of Teratogens in sediments of the Niagara river watershed as reflected by Chironomid (Diptera, Chironomidae) deformities. $J$. Great Lakes Res., 18(3), 467-480. https://doi.org/10.1016/S0380-1330(92)71312-4

Fores, E. (1992). Nutrient loading \& drainage channel response in a rice field system. Hydrobiologia, 230, 193-200. https://doi.org/10.1007/BF00036565

Guha, D. K., Chaudhuri, P. K., \& N\&i, S. K. (1982). Taxonomic studies of Chironominae (Chironomidae, Diptera) from West Bengal, Genus Dicrotendipes Kieffer. Proc. Zool. Soc. Calcutta, 33, 29-38. Accession: 001260713

Hamilton A. L., \& Sæther, O. A. (1971). The occurrence of characteristic deformities in the chironomid larvae of several Canadian lakes. Can. Entomol., 103, 363-368. https://doi.org/http://dx.doi.org/10.4039/Ent103363-3

Janssens de Bisthoven, L., \& Gerhardt, A. (2003). Chironomidae (Diptera, Nematocera) fauna in three small streams of Skania, Sweden. Environ. Monit. Assess., 83, 89-102. PMID: 12666723

Janssens de Bisthoven, L., Postma, J., Vermeulen, A., Goemans, G., \& Ollevier, F. (2001). Morphological deformities in Chironomus riparius meigen larvae after exposure to cadmium over several generations. Water Air Soil Poll., 129, 167-179. https://doi.org/10.1023/A:1010367524314

Janssens de Bisthoven, L., Nuyts, P., Goddeeris, B., \& Ollevier, F. (1998). Sublethal parameters in morphologically deformed Chironomus larvae, clues to understanding their bioindicator value. $\quad$ Freshwater $\quad$ Biol., $\quad 39, \quad 179-191$. https://doi.org/10.1046/j.1365-2427.1998.00265.x

Janssens de Bisthoven, L., Thimmermans, K. R., \& Ollevier, F. (1992). The concentration of cadmium, lead, copper \& zinc in Chironomus gr thummi larvae (Diptera, Chironomidae) with deformed versus normal menta. Hydrobiologia, 239, 141-149. https://doi.org/10.1007/BF00007671

Johnson, R. K., Wiederholm, T., \& Rosenberg, D. M. (1993). Freshwater biomonitoring using individual organisms, population \& species assemblages of benthic macroinvertebrates. In, Rosenberg D. M. \& Resh V.H. (eds). Freshwater biomonitoring \& benthic macroinvertebrate. Chapman \& Hall., 40-158.

Koehn, T., \& Frank, C. (1980). Effect of the thermal pollution on the chironomid fauna in an urban channel. In, D. A. Murray (ed) Chironomidae, Ecology, Systematics, Cytology \& Physiology, Pergamon Press, Oxford \& New York, 187-194. https://doi.org/10.1007/BF00007671 
Kownacki, A., Szarek-Gwiazda, E., \& Woźnicka, O. (2015). The importance of scanning electron microscopy (SEM) in taxonomy \& morphology of Chironomidae (Diptera) European Journal of Environmental Sciences, 5(1), 41-44. http://dx.doi.org/10.14712/23361964.2015.75

Lenat, D. R. (1993). Using mentum deformities of Chironomus larvae to evaluate the effects of toxicity \& organic loading in streams. J. North Am. Benthol. Soc., 12, 265-269. https://doi.org/10.2307/1467461

Lim, R. P. (1990). Effects of pesticides on the aquatic invertebrate community in rice fields. Proceedings of the International Conference on Tropical Biodiversity in Harmony with Nature, Malaysia, 336-352.

Lim, R. P., Abdullah, M. F., \& Fern\&o, C. H. (1984). Ecological studies of cladocera in rice fields of Tanjung Karang, Malaysia, subject to pesticide treatment. Hydrobiologia, 113, 99-103. https://doi.org/10.1007/BF00026596

MacDonald, E. E., \& Taylor, B. R. (2006). Incidence of mentum deformities in midge larvae (Diptera, Chironomidae) from North Nova Scotia, Canada. Hydrobiologia, 563, 277-287. https://doi.org/10.1007/s10750-006-0012-8

Madden, C. P., Sutter, P. J., Nicholson, B. C., \& Austin, A. D. (1992). Deformities in chironomid larvae as indicators of pollution (pesticide) stress. Nether. J. Aquat. Ecol., 26(2-4), 551-557. doi: 10.1007/BF02334251

Martinez, E. A., Moore, B. C., Schaumloffel, J., \& Dasgupta, N. (2004). Teratogenic versus mutagenic abnormalities in chironomid larvae exposed to zinc \& lead. Arch. Environ. Contam. Toxicol., 47, 193-198. https://doi.org/10.1007/s00244-016-0293-5

Morais, S. S., Molozzi, J., Viana, T. H., \& Callisto, M. (2010). Diversity of larvae of littoral Chironomidae (Diptera, Insecta) \& their role as bioindicators in urban reservoirs of different trophic levels. Braz. J. Biol., 70(4), 995-1004. https://doi.org/10.1590/S0034-71081999000300017

Morse, J. C., Bae, Y. J., Munkhjargal, G., SangpraDub, N., Tanida, K., Vshivkova, T. S., Wang, B., Yang, L., \& Yule, C. M. (2007). Freshwater biomonitoring with macroinvertebrates in East Asia. Frontiers Ecol. Environ., 5, 33-42. https://doi.org/10.1890/1540-9295-12.10.592

Nazarova, L. B., Rish, H. W., Kahlheber, A., \& Werding, B. (2004). Some observations of Buccal Deformities in chironomid larvae (Diptera, Chironomidae) from the Cienaga Gr\&e De Santa Marta, Colombia. Caldasia, 26(1), 275-290. doi:.org/10.15446/caldasia.v37n2.53594

Rebechi, D., \& Navarro-Silva, M. A. (2012). Setting the reference for the use of Chironomus sancticaroli (Diptera, Chironomidae) as bioindicator, Ontogenetic pattern of larval head structures. Zoologia, $29(2)$ $167-171$. https://doi.org/http://dx.doi.org/10.1590/S1984-46702012000200009 
Servia, M. J., Cobo, F., \& Gonzalez, M. A. (2000). Seasonal \& interannual variations in the frequency \& severity of deformities in larvae of Chironomus riparius (Meigen, 1804) \& Prodiamesa olivacea (Meigen, 1818) (Diptera, Chironomidae) collected in a polluted site. Environ. Monit. Assess., 64, 617-626. https://doi.org/10.1023/A:1006333808107

Servia, M. J., Cobo, F., \& Gonzalez, M. A. (2004a). Effects of short-term climatic variations on fluctuating asymmetry levels in Chironomus riparius larvae at a polluted site. Hydrobiologia, 523, 137-147. https://doi.org/10.1023/B:HYDR.0000033101.78277.8b

Servia, M. J., Cobo, F., \& Gonzalez, M. A. (2004b). Multiple- trait analysis of fluctuating asymmetry levels in anthropogenically \& naturally stressed sites, A case study using Chironomus riparius Meigen, 1804 larvae. Environ. Monit. Assess., 90, 101-112. PMID: 15887366

Vermeulen, A. C. (1995). Elaboration of chironomid deformities as bioindicators of toxic sediment stress, The potential application of mixture toxicity concepts. Ann. Zool. Fenn., 32, 265-285. https://doi.org/10.1007/BF00319404

Veroli, A. D., Selvaggi, R., \& Goretti, E. (2012). Chironomid mouthpart deformities as indicator of environmental quality, a case study in Lake Trasimeno (Italy). J. Environ. Monit., 14, 1473-1478. https://doi.org/10.1039/C2EM30572K

Veroli, A. D., Selvaggi, R., Pellegrino, R. M., \& Goretti, E. (2010). Sediment toxicity \& deformities of chironomid larvae in Lake Piediluco (Central Italy). Chemosphere, 79, 33-39. doi: 10.1016/j.chemosphere.2010.01.057

Warwick, W. F., \& Tisdale, N. A. (1988). Morphological deformities in Chironomus, Cryptochironomus, \& Procladius (Diptera, Chironomidae) from two differentially stressed sites in Tobin lakes, Saskatchewan. Can. J. Fish. Aquat. Sci., 45, 1123-1144. doi:10.5061/dryad.f3b66

Warwick, W. F. (1980). Pasqua lake, southeastern Saskatchewan, a preliminary assessment of trophic status \& contamination based on the Chironomidae (Diptera). In, D. A. Murray (ed) Chironomidae, Ecology, Systematics, Cytology \& Physiology, Pergamon Press, Oxford \& New York. 255-267. https://doi.org/10.1002/iroh.19810660626

Warwick, W. F. (1985). Morphological abnormalities in Chironomidae (Diptera) larvae as measures of toxic stress in freshwater ecosystems, indexing antennal deformities in Chironomus Meigen. Can. J. Fish. Aquat. Sci., 42, 1881-1941. https://doi.org/10.5061/dryad.f3b66

Warwick, W. F. (1988). Morphological deformities in Chironomidae (Diptera) larvae as biological indicators of toxic stress. In, M.S. Evans (Ed.). Toxic contaminants \& ecosystem health. A Great Lake focus. Wiley \& Sons, New York. 281-320. https://doi.org/10.3354/meps046167

Warwick, W. F. (1990). Morphological deformities in Chironomidae (Diptera) larvae from the Lac St. Louis \& Laprairie basins of the St. Lawrence River. J. Gt. Lakes Res., 16(2), 185-208. 
https://doi.org/10.1016/S0380-1330(90)71413-X

Warwick, W. F. (1991). Indexing deformities in ligulae \& antennae of Procladius larvae (Diptera, Chironomidae), Application to contaminant-stressed environments. Can. J. Fish. Aquat. Sci., 48, 1151-1166. https://doi.org/10.5061/dryad.f3b66

Wiederholm, T. (1984). Incidence of deformed chironomid larvae (Diptera, Chironomidae) in Swedish lakes. Hydrobiologia, 109, 243-249. https://doi.org/10.1007/BF00007742

Wirth, W. W. \& Marston, N. (1968). A method for mounting small insects on microscope slides in Canada balsam. Ann. Entomol. Soc. Am., 61, 783-784 http://dx.doi.org/10.1093/aesa/sav115 
Table 1. Physico-chemical characteristics of sampling sites during 2012 (Aman) to 2014 (Boro)

\begin{tabular}{|c|c|c|c|c|c|c|c|c|c|c|c|}
\hline Year & Month & Week & Relative Humidity (\%) & & Air Temp $\left({ }^{\circ} \mathrm{C}\right)$ & & Rainfall (cm) & Water Temp $\left({ }^{\circ} \mathrm{C}\right)$ & Water pH & Soil pH & Water DO (mg/l) \\
\hline Season & & & Max & Min & $\operatorname{Max}$ & Min & & & & & \\
\hline 2012 & July & 1 & 89.85 & 74.42 & 33.25 & 26 & 4.82 & 27.5 & 7.1 & 6.1 & 4.3 \\
\hline \multirow[t]{9}{*}{ AMAN } & & 2 & 92.42 & 73.35 & 32.81 & 25.8 & 28.72 & 28.01 & 7.5 & 5.7 & 7.5 \\
\hline & & 3 & 91.42 & 72.14 & 31.42 & 25.38 & 10.92 & 27 & 7.4 & 5.9 & 6.34 \\
\hline & & 4 & 92.57 & 78.28 & 32.12 & 25.97 & 20.86 & 27.7 & 7.4 & 6.3 & 8 \\
\hline & Aug & 1 & 92.16 & 74.16 & 31.77 & 25.5 & 6.81 & 26 & 7.1 & 6.1 & 7.5 \\
\hline & & 2 & 94.14 & 82.57 & 31.32 & 25.58 & 17.6 & 26.6 & 7.2 & 6.2 & 7.7 \\
\hline & & 3 & 95.28 & 76 & 32.14 & 25.64 & 18.08 & 27.2 & 7.1 & 6.4 & 8.3 \\
\hline & & 4 & 95.28 & 76.57 & 31.91 & 25.57 & 4.78 & 26.8 & 7.3 & 6.1 & 6.02 \\
\hline & Sept & 1 & 95.33 & 70 & 32.31 & 25.83 & 5.36 & 27 & 7.4 & 5.7 & 6.45 \\
\hline & & 2 & 92 & 69 & 32 & 25 & 4.65 & 26 & 7.3 & 5.9 & 7 \\
\hline 2013 & Jan & 3 & 92 & 49 & 23 & 9.7 & 0.16 & 15.2 & 7.1 & 5.2 & 5.1 \\
\hline \multirow[t]{9}{*}{ BORO } & & 4 & 91 & 49 & 24 & 9.7 & 0 & 15.4 & 7.4 & 5.4 & 6 \\
\hline & Feb & 1 & 92 & 42 & 24 & 12.9 & 0 & 16 & 7.6 & 5.6 & 6.45 \\
\hline & & 2 & 93 & 41 & 26.9 & 12.9 & 0.8 & 16.5 & 7.3 & 6 & 7 \\
\hline & & 3 & 93 & 43 & 27 & 13 & 0 & 16.8 & 7.3 & 5.9 & 7.09 \\
\hline & & 4 & 92 & 40 & 27 & 12 & 0 & 17.3 & 7.1 & 6.2 & 6.4 \\
\hline & March & 1 & 93 & 40 & 34 & 13 & 0 & 17 & 6.9 & 6.1 & 5.9 \\
\hline & & 2 & 93.5 & 39 & 33.8 & 16.9 & 0.06 & 17.4 & 7.2 & 6 & 5.7 \\
\hline & & 3 & 92 & 41 & 34 & 15 & 0 & 17.8 & 7.3 & 6.2 & 6 \\
\hline & & 4 & 91 & 42 & 34 & 16 & 0 & 18.5 & 7.1 & 6.1 & 6.5 \\
\hline 2013 & July & 1 & 91.85 & 63.57 & 33.21 & 26.34 & 0.17 & 28.1 & 6.9 & 5.6 & 5.7 \\
\hline \multirow[t]{9}{*}{ AMAN } & & 2 & 90.42 & 60.35 & 34.17 & 26.12 & 1.97 & 27.2 & 7.1 & 5.6 & 6.2 \\
\hline & & 3 & 91.28 & 61.42 & 33.92 & 26 & 0.45 & 26.9 & 7.2 & 5.8 & 7.32 \\
\hline & & 4 & 89.57 & 77.85 & 31.8 & 25.72 & 10.22 & 27.5 & 7.1 & 5.7 & 7.1 \\
\hline & Aug & 1 & 83.85 & 72.42 & 31.85 & 25.42 & 7.62 & 27 & 7.3 & 6 & 7.29 \\
\hline & & 2 & 84.85 & 78.14 & 31.25 & 25.7 & 13.92 & 26.5 & 7.5 & 6.3 & 7.45 \\
\hline & & 3 & 92.5 & 79.66 & 32.68 & 25.57 & 9.51 & 27.4 & 7.2 & 6.2 & 6.7 \\
\hline & & 4 & 93.5 & 78 & 30.22 & 24.44 & 17.08 & 27.9 & 7.3 & 6.3 & 7.2 \\
\hline & Sept & 1 & 91.57 & 73 & 32.04 & 25.41 & 21.51 & 27.7 & 7.6 & 6.1 & 7.25 \\
\hline & & 2 & 92.57 & 69.85 & 33.32 & 25 & 16.57 & 26.9 & 7.4 & 6.2 & 7.4 \\
\hline 2014 & Jan & 3 & 88.1 & 42.16 & 23.86 & 11.63 & 0 & 16 & 7.4 & 5.6 & 7.19 \\
\hline \multirow[t]{9}{*}{ BORO } & & 4 & 88.14 & 37.14 & 24.84 & 11.07 & 0 & 15 & 7.1 & 5.9 & 6.9 \\
\hline & Feb & 1 & 87.71 & 29.85 & 27.02 & 11.41 & 0 & 16.4 & 7 & 6 & 6.5 \\
\hline & & 2 & 87.42 & 29.64 & 27.75 & 14.7 & 0 & 16.9 & 7.2 & 5.8 & 7 \\
\hline & & 3 & 85.28 & 47.42 & 23.68 & 13.8 & 6.85 & 16.5 & 7.1 & 6 & 7.3 \\
\hline & & 4 & 86.85 & 38.85 & 27.58 & 17.4 & 0.74 & 17.8 & 7.5 & 6.2 & 7.1 \\
\hline & March & 1 & 84 & 38.71 & 25.85 & 16.58 & 0.37 & 18 & 7.1 & 6.1 & 6.9 \\
\hline & & 2 & 85.57 & 30.85 & 30.96 & 18.1 & 0 & 18.8 & 7.2 & 6.4 & 6.35 \\
\hline & & 3 & 83.14 & 33.45 & 28.85 & 19.41 & 0 & 19 & 7.1 & 6.2 & 6.08 \\
\hline & & 4 & 87.71 & 35.28 & 30.77 & 21.67 & 6.08 & 19.2 & 7.4 & 6 & 5.67 \\
\hline
\end{tabular}



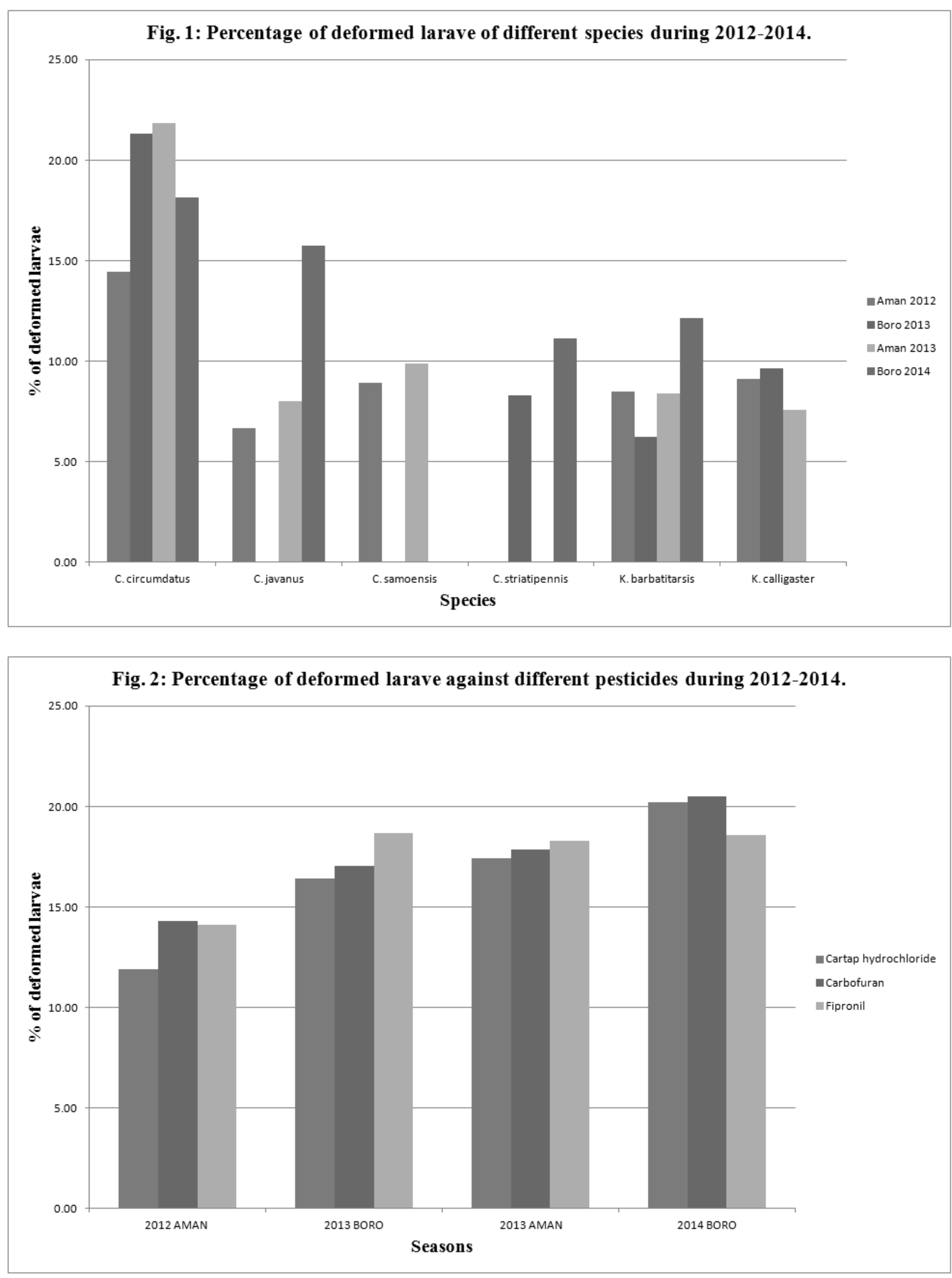


\section{Macrothink}

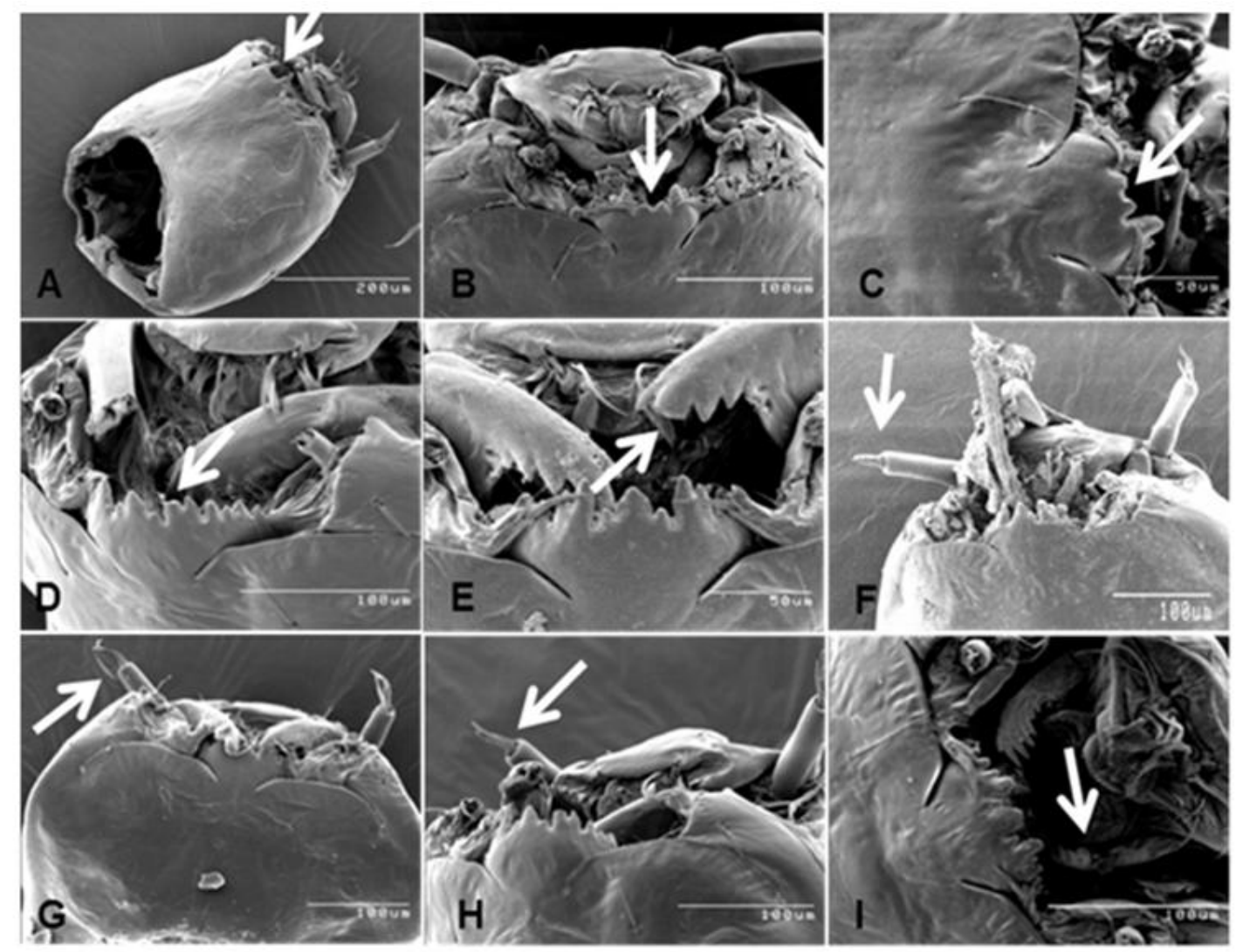

Fig, 3 : SEM Micrograph of Several deformed parts of head capsule of Chironomid larvae. (A,B, $C \&$ D)-Mentum, (E)-Mandible, (F, G \& H )-Antenna, (I) Premandible.

\section{Copyrights}

Copyright for this article is retained by the author(s), with first publication rights granted to the journal.

This is an open-access article distributed under the terms and conditions of the Creative Commons Attribution license (http://creativecommons.org/licenses/by/4.0/) 